\title{
NETWORK SECURITY ARCHITECTURE AND APPLICATIONS BASED ON CONTEXT-AWARE SECURITY
}

\author{
Hoon $\mathrm{Ko}^{1}$, Chang $\mathrm{Choi}^{2}$, Pankoo $\mathrm{Kim}^{3}$ and Junho Choi ${ }^{4}$ \\ ${ }^{1}$ IT Research Institute, Chosun University, Gwangju, South Korea \\ ${ }^{2}$ IT Research Institute, Chosun University, Gwangju, South Korea \\ ${ }^{3}$ Department of Computer Engineering, Chosun University, Gwangju, South \\ Korea \\ ${ }^{4}$ Division of Undeclared Majors, Chosun University, Gwangju, South Korea
}

\begin{abstract}
The number of services and smart devices which require context is increasing, and there is a clear need for new security policies which provide security that is convenient and flexible for the user. In particular, there is an urgent need for new security policies regarding IT vulnerability layers for children, the elderly, and the disabled who experience many difficulties using current security technology. For a convenient and flexible security policy, it is necessary to collect and analyze data such as user service use patterns, locations, etc., which can be used to distinguish attack contexts and define a security service provision technology which is suitable to the user. This study has designed a user context-aware network security architecture which reflects the aforementioned requirements, collected user context-aware data, studied a user context analysis platform, and studied and analyzed context-aware security applications.
\end{abstract}

\section{KEYWORDS}

Context-aware Security, Network Security Policy, Malicious Code Detection

\section{INTRODUCTION}

As the internet of things develops and becomes commercialized, security threats targeting a variety of mobile smart devices are increasing. Among the threats currently being introduced are attacks which can install malicious code on washing machines and refrigerators, attacks which allow hackers to illegally control automobiles remotely, and security vulnerabilities in medical devices such as pacemakers. However, the security solutions for responding to these threats have not taken user convenience into account, and users are inconvenienced by them as a result. It is believed that in the future all devices will connect to networks at high speeds, and the problem of network security will become more important. Children, the elderly, and the disabled in particular must be considered, as they experience difficulties in understanding and using current security solutions. Current security studies are being conducted toward the end of increasing user convenience while maintaining system security. The goal is to resolve the underlying problem by accurately understanding the principles related to security threats and providing the security factors which current solutions omit or fail to satisfy. The user context-aware network security Dhinaharan Nagamalai et al. (Eds) : ACSIT, SIPM, ICITE, ITCA - 2019

pp. 79-90, 2019. (C) CS \& IT-CSCP 2019

DOI: $10.5121 /$ csit.2019.90308 
solution proposed in this study is a security framework which can simultaneously provide convenience and security to the normal user. It collects information which can determine the user's context such as user location information, service use patterns, etc., and it automatically provides the most appropriate security service to the user. This paper describes the user contextaware technology that is needed to collect data from the user device's sensors and nearby communications devices and becomes aware of the user context through machine learning and real-time big data analysis technology in order to provide optimized security services.

\section{User ConteXt-Aware Network Security Technology TrendS}

\subsection{Context DeFinition}

Context describes the situation that an entity is experiencing, and context can be collected to analyze a scenario. There are various kinds of context such as people, places, and things. Context is categorized as physical or logical according to its nature, as shown in Table 1.

Table 1. Context Categories.

\begin{tabular}{|c|c|c|}
\hline Category & Physical Context Data & Logical Context Data \\
\hline $\begin{array}{c}\text { Acquisition } \\
\text { Method }\end{array}$ & $\begin{array}{c}\text { Acquired through sensors; sensors } \\
\text { observe status through measurements }\end{array}$ & $\begin{array}{c}\text { Acquired through record data and } \\
\text { activity situation }\end{array}$ \\
\hline Processing & $\begin{array}{c}\text { For example, magnetic sensors } \\
\text { measure a magnetic field's strength } \\
\text { and direction, and inertia sensors } \\
\text { measure angular displacement and } \\
\text { changes in angular displacement }\end{array}$ & $\begin{array}{c}\text { For example, the data indicates } \\
\text { whether a person is performing an } \\
\text { activity or resting, or whether the } \\
\text { person is talking on the phone or } \\
\text { sending a message, etc. }\end{array}$ \\
\hline
\end{tabular}

\subsection{Data Collection}

The types of data which can be collected by a device are very diverse, but the problems with collected data such as integrity, availability, user privacy, etc. are also very diverse. Table 2 shows recent studies related to data collection.

Table 2. Data Collection.

\begin{tabular}{|c|c|c|c|c|c|}
\hline Category & $\begin{array}{c}\text { People-centric } \\
\text { Opportunistic } \\
\text { Sensing [1] }\end{array}$ & $\begin{array}{c}\text { The } \\
\text { algorithmic } \\
\text { foundations of } \\
\text { differential } \\
\text { privacy [2] }\end{array}$ & $\begin{array}{c}\text { Continuous } \\
\text { user } \\
\text { authentication } \\
\text { on mobile } \\
\text { devices [3] }\end{array}$ & $\begin{array}{c}\text { Soft } \\
\text { authentication } \\
\text { with low-cost } \\
\text { signatures [4] }\end{array}$ & $\begin{array}{c}\text { Joint } \\
\text { segmentation } \\
\text { and activity } \\
\text { discovery using } \\
\text { semantic and } \\
\text { temporal priors } \\
{[5]}\end{array}$ \\
\hline Feature & $\begin{array}{c}\text { When the } \\
\text { results of } \\
\text { devices } \\
\text { performing } \\
\text { sensing are } \\
\text { accessed by } \\
\text { Wi-Fi, they }\end{array}$ & $\begin{array}{c}\text { Device's own } \\
\text { security and } \\
\text { user privacy }\end{array}$ & $\begin{array}{c}\text { Use of wrist } \\
\text { motion } \\
\text { sensor's } \\
\text { accelerometer } \\
\text { (hallmark } \\
\text { usage) }\end{array}$ & $\begin{array}{c}\text { Comparison } \\
\text { of behavior } \\
\text { patterns of } \\
\text { registered } \\
\text { smartphone } \\
\text { owner and } \\
\text { illegal user }\end{array}$ & $\begin{array}{c}\text { Uses non- } \\
\text { parametric } \\
\text { integrated } \\
\text { model, divides } \\
\text { time into } \\
\text { specific } \\
\text { segments and }\end{array}$ \\
\hline
\end{tabular}




\begin{tabular}{|c|c|c|c|c|c|}
\hline & $\begin{array}{l}\text { are sent to the } \\
\text { database } \\
\text { server and } \\
\text { data is } \\
\text { collected }\end{array}$ & & & & $\begin{array}{l}\text { uses time points } \\
\text { where activities } \\
\text { are changing }\end{array}$ \\
\hline Advantages & $\begin{array}{c}\text { Data } \\
\text { collection is } \\
\text { possible even } \\
\text { though } \\
\text { separate } \\
\text { infrastructure } \\
\text { is not } \\
\text { allocated }\end{array}$ & $\begin{array}{l}\text { Strengthens } \\
\text { security of } \\
\text { Android } \\
\text { market }\end{array}$ & $\begin{array}{l}\text { No need for } \\
\text { passwords, } \\
\text { fingerprints or } \\
\text { RFID tags }\end{array}$ & $\begin{array}{c}\text { Higher } \\
\text { accuracy than } \\
\text { existing } \\
\text { methods when } \\
\text { noise of } \\
\text { sensor results } \\
\text { is below a } \\
\text { fixed level }\end{array}$ & $\begin{array}{l}\text { Flexible segment } \\
\text { size possible by } \\
\text { specifying one } \\
\text { super sample }\end{array}$ \\
\hline Disadvantages & $\begin{array}{l}\text { Problems } \\
\text { related to } \\
\text { participants' } \\
\text { privacy, data } \\
\text { integrity, and } \\
\text { usability }\end{array}$ & $\begin{array}{c}\text { User } \\
\text { information } \\
\text { leaks when } \\
\text { requesting } \\
\text { permission to } \\
\text { access specific } \\
\text { information on } \\
\text { the devices } \\
\text { during app } \\
\text { installation }\end{array}$ & $\begin{array}{l}\text { Accuracy } \\
\text { increases only } \\
\text { if the time } \\
\text { when the user } \\
\text { uses the object } \\
\text { and the time } \\
\text { when the wrist } \\
\text { motion sensor } \\
\text { collects the } \\
\text { data are the } \\
\text { same }\end{array}$ & $\begin{array}{l}\text { There is still } \\
\text { battery } \\
\text { consumption, } \\
\text { and usage } \\
\text { range } \\
\text { (coverage) is } \\
\text { limited }\end{array}$ & $\begin{array}{l}\text { Higher accuracy } \\
\text { than existing } \\
\text { methods when } \\
\text { noise of sensor } \\
\text { results is below } \\
\text { a fixed level }\end{array}$ \\
\hline
\end{tabular}

\section{A. SECURITY INFORMATION / EVENT MANAGEMENT}

Systematic measures are necessary to perform early detection and respond to the various security threats that use advanced/large-scale network infrastructure. It is also necessary to have a security control system which collects large amounts of event data such as logs, packets, etc. generated by various security devices, network infrastructure, server/storage devices, and service applications, and which uses big data solutions to perform security analysis. Security Information and Event Management (SIEM) is a commercially-oriented solution which collects virtual/actual networks, service applications, system logs and event data. It then categorizes these and analyzes them to create quick reports, and it gives warnings if an additional intervention or altered response is needed [6][7][8][9]. The security tools provided by SIEM perform the core role of a security operations center (SOC) which performs central duties related to security in an organization or business' IT structure. It is also used to record security logs and generate compliance reports [9].

\section{B. Trends in Security Collection/Analysis TeChNology Using The ClOUd}

In Security as a Service (SESaaS), the security service provider takes responsibility, and services are provided for authentication, anti-virus, anti-malware/spy-ware, intrusion detection, and security event management [10]. In cloud computing, this is defined as Cloud Security as a Service or SECaaS in which the cloud provider (CP) provides security in the form of SESaaS. The services are categorized as shown in Figure 1. The provided services include identity and access management, data loss prevention, web security, email security, security assessments, intrusion management, security information and event management, encryption, business continuity and disaster recovery, and network security. 


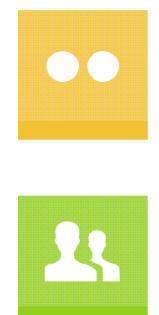

Business Continuity and Disaster Recovery

- The contingency plans and measures to ensure operational

resiliency

maintain the ability to quickly and reliably recover Cloud centric BC/DR makes use of the cloud's flexibility to minimize cost and maximize benefic

Service: file recovery provider, file backup provider, Replication

Email Security

- Provide control over inbound and outbound email

Policy-based encryption of emails digital signatures

Service: content security, anti-virus/anti-malware, spam

filtering, email encryption etc.

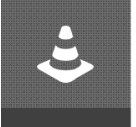

Identity and Access Management (IAM)

- Provide controls for assured identities and access

management
Service: user-centric ID provider, Federated IDs, Policy

provider, authorization management, Electronic signature etc.

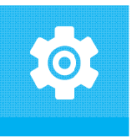

Network Security

- Security control at the network in aggregate

Requires tight integration with the hypervisor

Requires tight integration with the hypervisor

Security Information and Event Management (SIEM)

- Accept log, event and flow information from a diverse set of

devices

Conduct information security analysis, correlation

Real-time reporting and alerting on incidents/events

Service: log management, event correlation, security/incident

response, log and event storage, interactive searching and parsing of log data etc.

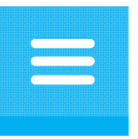

Data Loss Prevention (DLP)

- Monitoring, protecting, and verifying the security of data inuse(endpoint action), in-motion (network traffic), at-rest (dat

Storage) data encryption, dynamic data masking, policy controlled data access, multilingual fingerprinting etc.

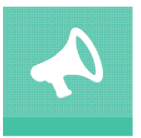

Encryption

- One of the most effective data protection controls

Critical customer and enterprise data could be held by third-party cloud providers in multi-tenant shared computing and storage environments

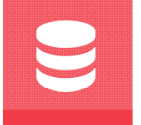

Intrusion Managemen

- Using pattern recognition to detect and react to statistically unusual events

Reconfiguring system components in real time to stop an

intrusion
Service: packet inspection, detection, prevention event correlation and pattern recognition, DPI etc.

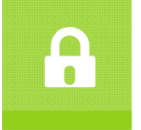

Security Assessment

- Third-party audits of cloud services or assessments of on-

premises system

- Compliance control for laaS, PaaS, and SaaS platforms

- Service: internal/external penetration test, application penetration test, host and quest assessments, virtual infrastructure assessment

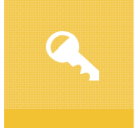

Web Security

- Proxying and redirecting web traffic to the cloud provide

- Added layer of protection for entering the enterprise via web

browsing

Service: web filtering, web monitoring, anti-phishing, email server anti-spam etc.

Figure 1. SECaaS WG defined 10 categories

\section{USEr ConteXt-Aware Network Security Structure Design}

\subsection{Considerations During ArChitecture Design}

Recently, there has been an increase in the device networks which need authentication in the IoT environment as well as the range of performance and usage environments for these devices. Because of this, it must be possible to use existing authentication methods in the proposed user context-aware network structure. The network security structure design considerations are shown in Table 3.

Table 3. User context-aware network structure design considerations.

\begin{tabular}{|c|l|}
\hline Considerations & \multicolumn{1}{c|}{ Features } \\
\hline $\begin{array}{c}\text { User usability } \\
\text { Issue }\end{array}$ & $\begin{array}{l}\text { Because smart devices are always carried by the user as they move around, usability } \\
\text { must be considered more for cases in which authentication occurs often [11] } \\
\text { In practice, user accessibility is decreased if errors such as false positives and false } \\
\text { negatives occur often or if it takes a long time to perform authentication and use the } \\
\text { device }\end{array}$ \\
\hline $\begin{array}{c}\text { Capacity issue } \\
\text { of Mobile } \\
\text { devices }\end{array}$ & $\begin{array}{l}\text { If there is no interface which provides knowledge-based or biometric-based } \\
\text { authentication methods due to the device characteristics: } \\
\text { It is necessary to entrust security related features to an external server such as a hub, } \\
\text { gateway, or cloud } \\
\text { There can be a problem with having to completely trust the entity which performs } \\
\text { this role, and higher security such as additional authentication is required }\end{array}$ \\
\hline
\end{tabular}




\begin{tabular}{|l|l|}
\hline \multirow{3}{*}{ Privacy issue } & $\begin{array}{l}\text { There is a possibility that GPS information which user data gives can expose the } \\
\text { user's location[12] } \\
\text { User call logs describe the user's personal relationships. } \\
\text { It is necessary to consider the privacy of users which have information }\end{array}$ \\
\hline
\end{tabular}

\subsection{Data Collection Architecture}

The device's sensors are used, and logs such as the user's contact information and text information are collected, and a behavior fingerprint is defined for each. For example, if the user is a student, the student's movement pattern may take a regular form such as moving between home and school. If the user accepts a phone call from an unregistered number, the probability that the number will be accepted in the future increases. If the user does not accept the call, the probability that it will not be accepted in the future increases. These user behavior patterns are used in the creation of a behavior fingerprint (BFP). BFPs which are created this way are called attributes. The accurate creation of attributes is more important than anything in increasing the accuracy of user authentication. This is because external factors such as the smartphone's location, user's behavior, current weather, temperature/humidity, etc. create noise, and this reduces accuracy when distinguishing the user. Therefore, in order to distinguish users by using attributes, confidence must be increased continually by combining nearby attributes and renewing them.

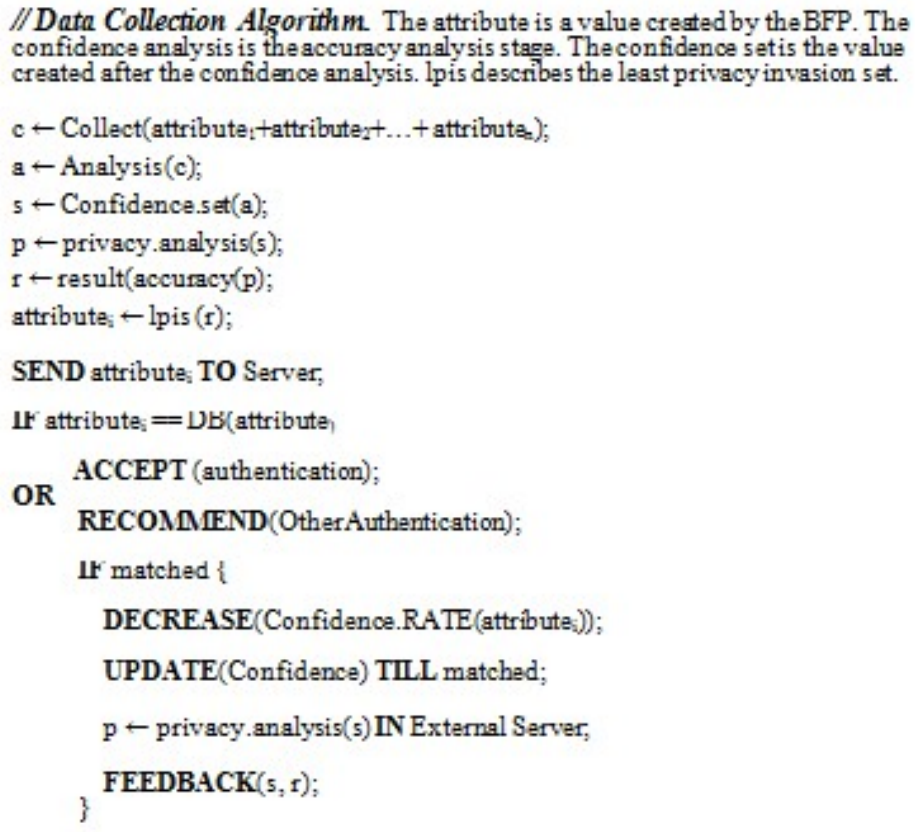

In the proposed architecture's processing order, the data is first collected according to the attribute, and then the confidence analysis is performed. The confidence analysis is a module which calculates whether a certain combination of attributes is necessary to guarantee confidence over a certain threshold value. Based on these calculations, the confidence set is created and analyzed. The privacy analysis analyzes the degree of privacy invasion for each attribute. The least privacy invasion set is selected, and the set's attributes are transmitted to an external server. 
The external server provides feedback on the confidence analysis and the privacy analysis based on the analyzed results. If the comparison with the fingerprint that the user has already saved does not produce a match, a different authentication method is proposed. If the different authentication method succeeds, the attribute's confidence is lowered, and the confidence is continually updated (FEEDBACK Step). In FEEDBACK, if privacy continually brings in the same result, similar attributes are continually sent out. However, because it is easy to violate privacy, the external server's feedback results are reflected in the privacy analysis to prevent transmission of the same attribute.

\subsection{Context-Aware Multi-Factor Authentication}

Multi-factor authentication requires different types of information on the authentication target in order to control access to a resource, such as information that the user knows and a possession that the user has [13]. This authentication method is already widely used. For example, a transaction with a bank's ATM card requires both knowledge (password -- information the user knows) and the ATM card (possession -- thing the user has) to confirm the user. Because 2 pieces of information are required, this corresponds to a type of multi-factor authentication known as two-factor authentication. If the user's context is used as one piece of authentication information in multi-factor authentication, the level of security can be maintained while also ensuring convenience. Information acquired as the result of soft sensing is used to determine the user context information. This method can confirm whether or not the device or environment which is to be authenticated matches the context experienced by the user, and the complexity of the authentication stage is only alleviated if it does match. If this method is used, an additional twofactor or three-factor authentication stage is required if the user context information does not match. By providing such a stage, a higher level of authentication security can be achieved. If the user context information does match, the authentication stages can be simplified to increase user convenience.

\section{USEr Context-Aware Network Security Structure Design}

\subsection{Definition of Data}

\section{A. Collection Devices}

In the IoT era, the number of sensor types and the places where they are used have both increased. Devices that users carry and connected sensors can extract features from the user's activities, behavior, etc. There are convenient and effective authentication methods which calculate a risk score and make requests for a suitable authentication approach according to the risk. Types of collection devices include smart phones, PCs, tablet PCs, wearable devices, smart sensors / hubs, smart door locks, smart TVs with IoT hubs, and other connected devices.

\section{B. Collectable Data}

Table 4 shows the collectable data. For example, a smartphone that a user carries or a wearable device can detect the user's location, activities, and characteristics through physical sensors (hard sensing) such as accelerometers, magnetometers, and gyroscopes. Effective authentication methods which are suitable for the user context can be requested through logical sensors (soft sensing) which detect screen state of devices, battery consumption, phone records, data usage, etc. 
Table 4. Collectable data.

\begin{tabular}{|l|l|l|}
\hline \multicolumn{1}{|c|}{ Device } & \multicolumn{1}{|c|}{ Sensors (Physical/ Logical) } & \multicolumn{1}{c|}{ Features } \\
\hline $\begin{array}{l}\text { Smartphone, PC and tablets/ } \\
\text { Wearables }\end{array}$ & $\begin{array}{l}\text { - Phone Info/Calls } \\
\text { - Location, Accelerometer } \\
\text { - Magnetometer }\end{array}$ & $\begin{array}{l}\text { User's current location and } \\
\text { activities }\end{array}$ \\
\hline Smart Sensors/ Hub & - Motion, Light & $\begin{array}{l}\text { User's environments and } \\
\text { activities }\end{array}$ \\
\hline Smart Door Lock & - Location & User at home or not \\
\hline Smart TV with IoT Hub & $\begin{array}{l}\text {-Usage time } \\
\text {-User channel properties, } \\
\text { etc. }\end{array}$ & $\begin{array}{l}\text { Duration, User's personal } \\
\text { interest }\end{array}$ \\
\hline
\end{tabular}

\subsection{SECURITY/PRIVACY ISSUES}

Context- aware opportunistic user authentication systems collect biometric contexts through the user's smart device and are able to understand the user's current context. By doing so, they have the compelling benefit of providing appropriate security solutions. However, by collecting this data, problems can occur which are related to user privacy and collected data integrity and usability. Also, as the use of smart devices increases, malicious apps may be offered on app markets. Even when an app is not malicious, mistakes by a developer who does not take security into account may cause problems in which users accidentally encounter other malicious programs through advertisements, etc. and expose their personal information [10]. If context- aware opportunistic user authentication is being used, there is a risk that the device may become a privacy vulnerability point (privacy hole) and even personal information stored on other connected devices could be leaked [14].

\subsection{Collection TeChNology}

Data collection for user context- awareness is categorized as physical sensor data which can be directly obtained from the devices that the user is operating, logical sensor data which changes according to the user's habits and device usage patterns, and soft sensing data in which new data is derived by using the data of several sensors [15][16]. Each type of sensor data can be collected continuously like GPS data or collected intermittently like phone conversation data. In short, there are many types of data for context awareness, and they have characteristics that make it difficult to integrate collection methods. As such, context-aware data requires analysis and processing before inferences which utilize the data can be made. Depending who is in charge of processing, this analysis includes (a) methods which directly process sensed data on the user device and (b) methods in which the user device sends data to a server and it is processed. The features of each method are shown in Table 5.

Table 5. Collection technology types.

\begin{tabular}{|l|l|l|}
\hline \multicolumn{1}{|c|}{ Type } & \multicolumn{1}{|c|}{ Advantages } & \multicolumn{1}{c|}{ Disadvantages } \\
\hline $\begin{array}{l}\text { (a) Data is processed } \\
\text { directly on the user device }\end{array}$ & $\begin{array}{l}\text { After processing, the size of the } \\
\text { data is reduced so that storing it } \\
\text { is easy and sending it to the } \\
\text { server is easy. }\end{array}$ & $\begin{array}{l}\text { The user device cannot guarantee sufficient } \\
\text { performance and it is difficult to update the } \\
\text { algorithms needed for data processing }\end{array}$ \\
\hline $\begin{array}{l}\text { (b) Data is sent to a server } \\
\text { and processed }\end{array}$ & $\begin{array}{l}\text { It is possible to guarantee } \\
\text { sufficient performance to process } \\
\text { the collected data. It is easy to } \\
\text { change the data characteristics or } \\
\text { analysis standards and update the } \\
\text { algorithm. }\end{array}$ & $\begin{array}{l}\text { The collected data must all be sent to the } \\
\text { server, which may put a burden on the user } \\
\text { device or server depending on the situation. }\end{array}$ \\
\hline
\end{tabular}




\subsection{Collection Technology}

Figure 2 shows the proposed data collection architecture. Confidence analysis analyzes the user fingerprint accuracy for each attribute. It can analyze 1 attribute or analyze the accuracy of a set of several attributes simultaneously. The accuracy analysis is first done on the basis of reference data, and later machine learning is used to continue learning about accuracy analysis. At first, an accuracy above a fixed level is seen. However, because the accuracy for each attribute can vary due to flaws in the sensors themselves or changes in user patterns, the accuracy is updated by setting a score for the accuracy based on the authentication results.

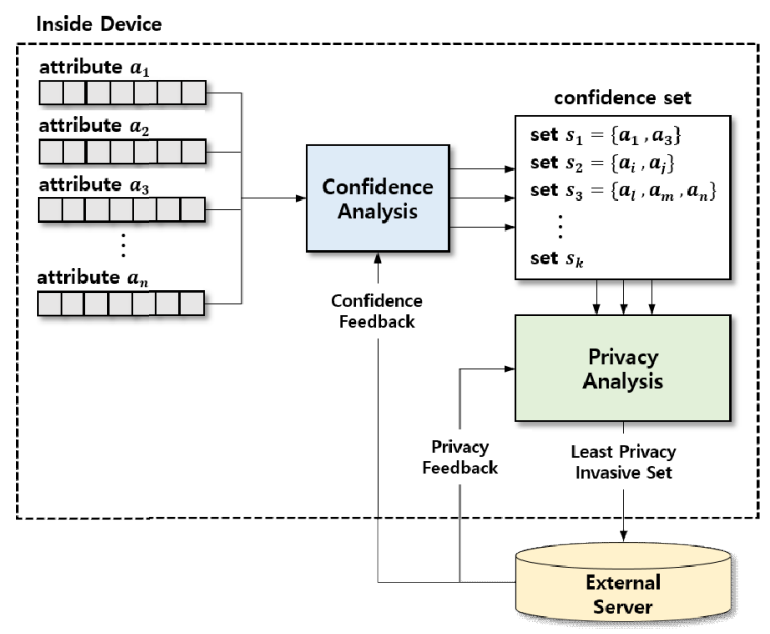

Figure 2. Data collection architecture

When confidence analysis is finished, a set of attributes which has an accuracy above a fixed threshold value is produced. The threshold value can be selected experimentally, and it can be updated later based on the authentication results. The set of attributes which is above the threshold value is called the confidence set. Privacy analysis is performed for a total of $\mathrm{k}$ confidence sets.

Privacy analysis shows the privacy given by the attributes in the confidence set. The user's sensitivity to the privacy of each attribute varies. Because the analysis of sensitivity to privacy varies by each user, different levels of sensitivity are used for each user. Providing high accuracy means distinguishing the user more easily, and this ultimately means showing the user's personal information more accurately. When the privacy analysis is finished, one set with the lowest sensitivity, i.e. the set with the least user privacy leaking, is selected. The selected set is defined as the least privacy invasive set, and it is transmitted to the external server for the next stage.

\section{Applications}

This section defines 5 context-aware applications based on the previously defined context-aware network security architecture and context-aware data collection method. These applications are context-aware authentication technology, context-aware access control technology, a contextaware personalized warning system, context-aware security settings, and a malicious code detection system. Table 6 describes each application. 
Table 6. Applications.

\begin{tabular}{|c|c|c|c|}
\hline Category & Goal & Processing & Features \\
\hline $\begin{array}{l}\text { Context- } \\
\text { aware } \\
\text { authentication } \\
\text { technology }\end{array}$ & $\begin{array}{l}\text { Provides a suitable } \\
\text { user context } \\
\text { authentication } \\
\text { process in which the } \\
\text { service user is pre- } \\
\text { enrolled to provide } \\
\text { context-aware } \\
\text { service to the user }\end{array}$ & $\begin{array}{l}\text { - Collects data from acceleration sensor, } \\
\text { microphone, GPS location service, and touch } \\
\text { screen for authentication } \\
\text { - The acceleration sensor measures the user's } \\
\text { movement state and speed. The microphone } \\
\text { receives the user's voice. } \\
\text { - The GPS can accurately know the user's } \\
\text { location. The touch screen collects the user's } \\
\text { touch behavior. The collected information is } \\
\text { used to perform authentication }\end{array}$ & $\begin{array}{l}\text { - Authentication using the user's } \\
\text { movement state } \\
\text { - Authentication using the user's } \\
\text { voice } \\
\text { - Authentication using the user's } \\
\text { GPS } \\
\text { - Authentication using the user's } \\
\text { touch records }\end{array}$ \\
\hline $\begin{array}{c}\text { Context- } \\
\text { aware access } \\
\text { control } \\
\text { technology }\end{array}$ & $\begin{array}{l}\text { Determines the } \\
\text { access control which } \\
\text { is suitable for the } \\
\text { context based on } \\
\text { context data } \\
\text { acquired by using a } \\
\text { variety of sensors, } \\
\text { GPS, etc. }\end{array}$ & $\begin{array}{l}\text { - The Profiler module extracts features from } \\
\text { collected raw data and defines objects related to } \\
\text { context models and profiles } \\
\text { - The Classifier module uses the extracted } \\
\text { features to train the context classification model } \\
\text { - Transmits the "classification" and the } \\
\text { "confidence value" which shows the degree of } \\
\text { risk in the context model to the Access Control } \\
\text { Layer } \\
\text { - The Access Control Layer module determines } \\
\text { access control based on the received data }\end{array}$ & $\begin{array}{l}\text { - Knows outdoor places that } \\
\text { the user visits often } \\
\text { - Knows indoor places that the } \\
\text { user visits often } \\
\text { - Integrates GPS data with } \\
\text { interactions between the user } \\
\text { and the device UI and } \\
\text { performs user location } \\
\text { analysis and current user } \\
\text { status analysis }\end{array}$ \\
\hline $\begin{array}{l}\text { Context- } \\
\text { aware } \\
\text { personalized } \\
\text { warning } \\
\text { system }\end{array}$ & $\begin{array}{l}\text { Provides custom } \\
\text { warnings according } \\
\text { to the user context } \\
\text { and effectively } \\
\text { conveys the warning } \\
\text { content to the user }\end{array}$ & $\begin{array}{l}\text { - Creates different warnings to transmit to the } \\
\text { user depending on the context analysis results } \\
\text { - Creates customized warnings which can } \\
\text { effectively convey warning content to the user } \\
\text { based on each context such as the level of } \\
\text { specialized knowledge possessed by the user, } \\
\text { the user's current status (working, sleeping, } \\
\text { resting, etc.), level of risk for abnormal } \\
\text { contexts, etc. }\end{array}$ & $\begin{array}{l}\text { - Warnings according to the } \\
\text { user's system specialty } \\
\text { - Warnings according to the } \\
\text { user's status } \\
\text { - Warnings according to the } \\
\text { warning context's risk level } \\
\text { - Bot detection warning: If the } \\
\text { user is not a person, } \\
\text { distinguishes the user as a bot } \\
\text { and creates a captcha }\end{array}$ \\
\hline $\begin{array}{l}\text { Context- } \\
\text { aware } \\
\text { security } \\
\text { settings }\end{array}$ & $\begin{array}{l}\text { Uses the user's } \\
\text { context-aware data } \\
\text { to resolve the hassle } \\
\text { of having to go } \\
\text { through a complex } \\
\text { security settings } \\
\text { process and provides } \\
\text { a dynamic and } \\
\text { simple security } \\
\text { settings method }\end{array}$ & $\begin{array}{l}\text { - Collects the user's context-aware data and uses } \\
\text { it to dynamically set the security settings level } \\
\text { of the devices used by the user according to the } \\
\text { situation } \\
\text { - The security settings levels are defined as } \\
\text { normal, high, and user-specified } \\
\text { - The context that is used to change the security } \\
\text { settings utilizes information such as the degree } \\
\text { to which the user understands security-related } \\
\text { information, the user's current status, the user's } \\
\text { activity data, and the user's location data }\end{array}$ & $\begin{array}{l}\text { - Security settings using user } \\
\text { status data } \\
\text { - Security settings using user } \\
\text { location data } \\
\text { - Security settings using user } \\
\text { activity data }\end{array}$ \\
\hline $\begin{array}{l}\text { Malicious } \\
\text { code } \\
\text { detection } \\
\text { system }\end{array}$ & $\begin{array}{l}\text { Provides malicious } \\
\text { code detection } \\
\text { system which is } \\
\text { customized } \\
\text { according to the user } \\
\text { status to establish } \\
\text { measures for } \\
\text { systematically } \\
\text { responding to and } \\
\text { preventing malicious } \\
\text { code attacks }\end{array}$ & $\begin{array}{l}\text { - Goes through static analysis, dynamic analysis, } \\
\text { and trace analysis and categorizes the features } \\
\text { which show the execution file as classes } \\
\text { - Determines groups which are estimated by the } \\
\text { relationship with the target execution file via } \\
\text { class categorization stage } \\
\text { - Categorizes the developer's classes based on } \\
\text { the data extracted from the execution file and } \\
\text { infers the developed and circulated execution } \\
\text { file from the specific structure }\end{array}$ & $\begin{array}{l}\text { - Malicious code detection } \\
\text { through static analysis } \\
\text { - Malicious code detection } \\
\text { through dynamic analysis } \\
\text { - Malicious code detection } \\
\text { through usage tracking }\end{array}$ \\
\hline
\end{tabular}




\section{Conclusions}

To implement user context-aware network security technology, it must be possible to determine contexts by utilizing user usage patterns and movement patterns which are based on user position data. To utilize safe user context awareness, data must be collected from the user device's sensors and nearby network devices, and the user's nearby context must be recognized by using machine learning and real-time big data analysis technology to provide optimized security service. In order to implement a safe user context-aware service, this study examined trends in context-aware network security technology and designed a user context-aware network security architecture. The trends in user context-aware network security technology were organized into data collection in which the collected data's integrity, usability, and user privacy are processed, context analysis which is an analysis stage for performing various analyses on the collected data, and contextbased applications which are for safely using the analyzed contexts. In the user context-aware network security architecture design, the context information analysis and the user's nearby context, which have been collected by the cloud server, were judged together to measure risk, and based on these results, security services which can deliver both user satisfaction and security were provided. In the results of the study, five kinds of applications were introduced, and the safety of the user context-aware applications were analyzed. Based on the results of this study, a variety of safe user context-aware applications are expected in the future.

\section{ACKNOWLEDGEMENTS}

This research was supported by Korea Electric Power Corporation (Grant number: R18XA06-12) and the National Research Foundation of Korea(NRF) grant funded by the Korea government(MSIP)(No.NRF-2016R1A2B4012638).

\section{REFERENCES}

[1] Berker Agir, Jean-Paul Calbimonte and Karl Aberer, "Semantic and Sensitivity Aware Location Privacy Protection for the Internet of Things," PrivOn'14 Proceedings of the 2nd International Conference on Society, Privacy and the Semantic Web - Policy and Technology, Vol. 1316, pp. 5863.

[2] Dwork, Cynthia, and Aaron Roth. "The algorithmic foundations of differential privacy," Foundations and Trends in Theoretical Computer Science 9.3-4 (2014): 211-407.

[3] Vishal M. Patel, Rama Chellappa, Deepak Chandra, and Brandon Barbello, "Continuous user authentication on mobile devices: Recent progress and remaining challenges," IEEE Signal Processing Magazine 33.4 (2016): 49-61.

[4] Buthpitiya, Senaka, Anind K. Dey, and Martin Griss. "Soft authentication with low-cost signatures," Pervasive Computing and Communications (PerCom), 2014 IEEE International Conference on. IEEE, 2014.

[5] Seiter, Julia, et al. "Joint segmentation and activity discovery using semantic and temporal priors," Pervasive Computing and Communications (PerCom), 2015 IEEE International Conference on. IEEE, 2015.

[6] “SIEM: A Market Snapshot,”Dr. Dobb's Journal, Feb. 2007.

[7] J. Hayes, "Cybersecurity and the Big Yellow Elephant," Cloudera Vision Blog, May 2015. 
[8] K. M. Kavanagh, O. Rochford, and T. Bussa, "Magic Quadrant for Security Information and Event Management," Gartner, Aug. 2016.

[9] Bhatt, P. K. Manadhata, and L. Zomlot, "The operational role of security information and event management systems," IEEE Security \& Privacy, vol. 12, no. 5, 2014.

[10] Mosaic Security Research, "Log Management \& Security Information and Event Management (SIEM) Software Guide,” Mosaic Security Research, (accessed May 2014).

[11] G. Abowd and A. Dey, "Towards a better understanding of context and context-Awareness," In International Symposium on Handheld and Ubiquitous Computing, pp. 304-307, 1999.

[12] H. Witte, C. Rathgeb and C. Busch, "Context-Aware Mobile Biometric Authentication based on Support Vector Machines," 2013 Fourth International Conference on Emerging Security Technologies, Cambridge, 2013, pp. 29-32.

[13] William E. Burr, Donna F. Dodson, Elaine M. Newton, Ray A. Perlner, W. Timothy Polk, Sarbari Gupta, and Emad A. Nabbus, "Electronic Authentication Guide," Special Publication 800-63-2, NIST, 2013.

[14] Kapadia, Apu, David Kotz, and Nikos Triandopoulos. "Opportunistic sensing: Security challenges for the new paradigm." 2009 First International Communication Systems and Networks and Workshops. IEEE, 2009.

[15] H. Witte, C. Rathgeb and C. Busch, "Context-Aware Mobile Biometric Authentication based on Support Vector Machines," 2013 Fourth International Conference on Emerging Security Technologies, Cambridge, 2013, pp. 29-32.

[16] T. Gisby, “”Soft” Sensors Are Breaking Into Four Major Industries,” Aug 2015.

[17] Harbach, Marian, et al. "Sorry, I don't get it: An analysis of warning message texts." International Conference on Financial Cryptography and Data Security. Springer Berlin Heidelberg, 2013.

[18] Anderson, Bonnie Brinton, et al. "How polymorphic warnings reduce habituation in the brain: Insights from an fMRI study." Proceedings of the 33rd Annual ACM Conference on Human Factors in Computing Systems. ACM, 2015. 


\section{Authors}

Hoon Ko received B.S. at Howon University in 1998, and M.S. in 2000, Ph.D. in 2004 at Soongsil University, S. Korea. He had worked at GECAD/ISEP/IPP in Portugal as a PostDoc from 2008 to 2013, and at J. E. Purkinje University, Czech Republic as a research professor from June 2013 to July 2015. Now he been working at IT Research Institute, Chosun University, S. Korea as a research professor since Oct 2017. His research area is CPS Security, Cyber-Security, context-aware, multicast, IoT, Bio-information security.

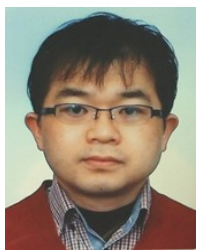

Chang Choi received his Ph.D. degree in Computer Engineering from Chosun University in 2012, and is now working as a research professor at the Chosun University, South Korea, and is a Senior member of the IEEE. His research interests include Intelligent Information Processing, Semantic Web, Smart IoT System and Intelligent System Security.

Pankoo Kim received his B.E. degree from the Chosun University in 1988 and M.S. and Ph.D. degrees in Ccomputer Engineering from Seoul National University in 1990 and 1994. Currently, He is now working as a full professor at Chosun University. He is an EIC of IT CoNvergence PRActice Journal. His specific interests include semantic web techniques, semantic information processing and retrieval, multimedia processing, semantic web and system security.

JunHo Choi received the PhD degree from Chosun University, Gwangju, Korea in 2004. He is currently an Assistant Professor with the Department of Undeclared Majors, Chosun University, Gwangju, Korea. His research interests include Security, Cloud Computing, Semantic Analysis, Ontology Modeling.
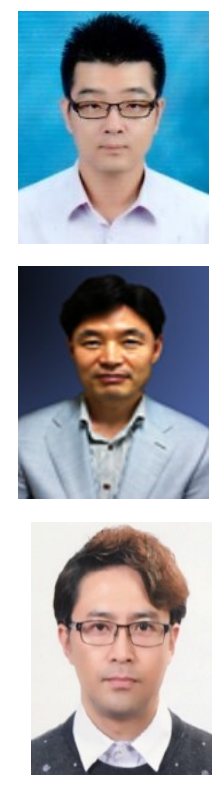